\title{
Discussion and Analysis of Anti-violation of Regulations in Electronic Power System
}

\author{
Zhang Shude, Zhou Xuelong, Zhang Shengsheng \\ Benxi Power Supply Company of National Grid Liaoning Electric Power Co., Ltd. \\ bxwl_650928@126.com
}

Keywords: Safe Operation; Anti-violation of Regulations

\begin{abstract}
Safe operation is a comprehensive work and violation of regulations is one of the great hidden dangers threatening safe operation, which includes management, device and behavior in violation of regulations. In recent years, the power enterprises have carried out extensive activities of anti-violation of regulations and gained some achievements. For the employees, such activities can guarantee the life safety of the personnel and safeguard their family happiness; for the enterprises, it ensures the safe and stable operation of power grid and enhances the healthy level of equipment, thus laying a solid foundation for enterprises to perform their social responsibilities, provide quality services and establish enterprise brand and good social image.

People with unsafe behaviors, staff in unsafe conditions and management and environment with deficiencies are the major causes of accidents. According to the experts, among all these factors, $70 \%$ to $80 \%$ of the accidents are caused by human factors. Habitual violation is believed as the major human factor and the prime culprit causing accidents of power enterprises.
\end{abstract}

\section{Measures for Anti-violation of Regulations}

Give top priority to the safety of employees.

(1) Reflect on the issues popping up in work

It is demanding to timely correct the actions in violation of regulations (such as the behavioral actions in violation of regulations); point out the behavioral actions in violation of regulations and inform them of all the employees through various forms; analyze the these actions and summarize the experience.

(2) Realize the serious results of violations

It is of prime importance to teach the employees the serious results of violations through media transmission. For example, the employees are shown the accident documentary and other relevant reports, especially the devastating accidents caused by unprofessional operations of the peer industry. At the same time, periodical safety education should be offered to the employees to enhance their understanding of the danger of unprofessional operation, eradicate the ideological roots of unprofessional operation and enable them to observe the various rules and regulations of their own free will and standardize their behaviors. By doing so, they will be keenly aware of the fact that the violation will bring infinite misery to themselves and their families.

(3) Enhance the enterprise's understanding of the importance of safe production and learn various rules and regulations

It is suggested to learn the various rules and regulations, especially the Regulation on Safe Operation in Electric Power Industry and intensify the training of the professional skills of employees and standardize each work step.

\section{Strengthen work management}

Intensify the "two tickets, three systems".

The "two tickets, three systems" is undoubtedly the most effect guarantee in electric power industry. 
(1) A rigorous and improved measure should be exercised for work handover. The consequences would be unthinkable if the unclear work handover and halfway examination cause mistaken switching of disconnecting link or power transmission.

(2) Clearly and accurately fill in the record. It is of prime importance to fill in the two tickets according to the facts.

(3) Fulfill responsibility. In the actual operation, the operator, superintendent and other personnel must exercise mutual supervision and perform their own functions.

\section{Improve the existing management systems.}

A strict, standardized and efficient management system and a network system featuring clear powers and responsibilities, distinct reward and punishment and in-place implementation are established so as to prevent the violators from exploiting an advantage. Grass-roots safety personnel shall be designated for some departments so as to guarantee the real-time supervision.

\section{Managers must strictly put into practice all the rules and regulations.}

The managers must stop any violation and prevent them from evolving into disasters. They must be scrupulous in separating public from private interests and seek truth from facts when executing the systems. The leaders should start from themselves and avoid commanding against rules.

\section{Deepen the origin of force in anti-violation of regulations}

\section{Create an environment favorable to the anti-violation of regulations.}

Expand training methods and lay a solid basis for the security of grassroots level. A safety thought is not sufficient for the effective self-supervision and control; at the same time, the real security ability is also of great importance. That is to say, the safety training is critical to an enterprise. By capitalizing on the existing human resources of enterprises, setting up the standardized management mechanism, carrying out the "top-down" training and putting into practice the regular security work, the safety ability of all the working staff will be improved. Training should focus on efficiency rather than simply the completion of a task. By following the steps of "refining standards, explaining standards and carrying out standards", the relevant personnel should innovate the training methods of safe operation so as to help the employees cultivate good operation habits. The author holds the idea that it is necessary to refine the standards and requirements involved in each filed operation and form the more systematic and complete textbook; then it is also advisable to make full use of the information technology to explain standards and form understandable, clear and direct video training textbook through dynamic whole-process behavior modeling; third, a number of activities, such as video creation, video education, simulated drill and contest appraisal is carried out to enhance the employees' understanding of the rules and regulations, help them master and observe the behavior standards in operation, reduce and eradicate behavior mistakes. Fourth, establish the synchronization mechanism to strengthen the executive force. The regulatory framework serves as the basis for normative operation; a notification process and learning process is needed from the printing to execution of each rule and regulation so as to enable the employees understand, master and execute the systems, synchronize the formulation of system with implementation of system. Each new rules and regulation should be subject to timely propagation and implementation. Through detailed explanation, the relevant personnel will receive beneficial guidance.

\section{Enhance the security quality of employees.}

Safety background. As a matter of fact, it is an important soft origin of force. It is demanding to ensure the supervisor-subordinate communication in daily management, encourage transpositonal consideration in the process of arranging work, arouse the safety awareness of the subordinates through guidance, encourage and incentive mechanism and inform them of the intentions of the supervisors. At the meantime, the supervisors should also gain access to the difficulties and requirements of the subordinates so as to offer necessary persuasion and eradication. Through top-down interaction and coordination, the subordinates and employees are willing to undertake the security duties. The violations will be fundamentally uprooted only by improving the self-regulation of all the employees. Achievements will be obtained in anti-violation of regulations only when the 
leaders, organizers and general employees set strict demands on themselves and follow the standards.

\section{Attach equal importance to treatment and standardization and create the safe operation environment.}

As the important site for production and operation, the operation operation environment will directly impact the personal and operation safety of the employees. Therefore, creating a safe operation environment is the undeniable responsibility of the managers of all levels. First, intensify investment and grapple with the essential safety issues. The safety evaluation and safety risk potential should be adopted to analyze the issues in field operation environment and essential safety of equipment, such as the unlocked crawling ladder of transformer station, failure of installing insulating sheath on busbar section and busbar cross section. The problems that may influence the personal safety should be resolutely avoided. Second, make the standards more strict and vigorously advance the standardized operation of safety facilities. It is demanding to standardize the implementation of operation environment, unify safety signs and equipment, attention line, graphical specification and configuration specification of safety protection so as to create a clear and safe working environment for the employees. Third, standardize management and intensify the safety protection equipment management for the employees. What's more, it is suggested to set up the management system and make clear the responsibility of each link, including the purchase, check and acceptance, experiment, sage, custody and abandonment and formulate allocation standard of safety equipment according to the professional features of work team.

\section{Exercise a combination of inflexibility and yielding to create a safe humanistic environment.}

Environment exerts substantial bearings on the behavior of people and nurtures life silently. The creation of a sound safe production environment directly, which can influence the psychological states of employees, plays an important role in strengthening safety awareness and consolidating compliance awareness and facilitates the implementation of anti-violation of regulations. First, positive guidance. The safety signs, warning signs and blessing signs are intensively pasted to arouse the intimacy and amiability. At the same time, it is suggested to carry out the activity of "sending safety culture to families" and build up defenses against anti-violation of regulations with the family responsibility; hold safety forum and address the audiences with safety-related topics and help the employees cultivate correct code of conduct with the safety events; set up good examples and build up "team without violations" to encourage the employees to observe the rules and regulations; Second, negative warnings are released and "redlining system" exercised for the serious violations. Propagation is extensively launched and special column for anti-violation set up to normalize the exposure of violations. Tough measures must be formulated for the serious and repeated violations. Meanwhile, the relevant department should offer in-depth analysis of the typical violations and strictly punish the abortive accidents. All these measures should be combined to cultivate the correct safety values and codes of conduct of the employees and strengthen and deepen the safety awareness.

\section{Conclusions}

This unpleasant situation is not brewed in a day. There are causes and background of many aspects for the reoccurrence of violations despite the repeated prohibitions. It is unrealistic to accomplish in an action; instead, the relevant personnel should build up confidence and follow a "people-oriented" approach so as to management people with institutions and handle issues with flow. Only by remaining steadfast in the work of anti-violations will the violations be permanently eradicated and basis for enterprise safety consolidated. 


\section{References}

[1] Eighteen Major Anti-Accident Measures of Power Grid from the State Grid Corporation of China [Z].

[2] Management of Construction Project [Z].

[3] The Compilation of Safety Management Clauses of the Construction Site in the State Grid Corporation of China [Z].

[4] Tian Yuping. Questions and Answers about Power Enterprise Breaking Rules and Regulations [M]. Beijing: China Electric Power Press, 2008.

[5] Li Donglai, Zhu Jianjun. The Rule and Precaution of the Phenomenon about Breaking Rules and Regulations [J]. China Power Enterprise Management, 2010.

[6] Huang Xianhua. A Brief Analysis about the Application of Violation of Regulations in the Management of Power Safety Production [J]. China Electric Power Education, 2009. 